\title{
Long-term Studies of Ciliate-Bacterial Interactions: Use of a Chemostat Fed with Bacteria Grown in a Separate Chemostat
}

\author{
By A. SAMBANIS† AND A. G. FREDRICKSON* \\ Department of Chemical Engineering and Materials Science, University of Minnesota, \\ Minneapolis, MN 55455, USA
}

(Received 12 August 1986; retised 23 January 1987)

\begin{abstract}
Two-stage chemostat cascades have been used to study growth of the ciliate Tetrahymena pyriformis on Escherichia coli over extended periods of time. Upward drifts (continuous, slow, uni-directional changes) of ciliate number density and downward drifts of ciliate mean cell size and density of residual bacteria occurred for many generations of ciliates before steady states were obtained. Ciliate chemostats were operated at two different dilution rates. Rates of drift were slower, and drifts persisted longer, both in terms of time and in terms of numbers of generations, in the chemostats operated at the higher dilution rate. Some speculations on the origins of the drifts are presented.
\end{abstract}

\section{INTRODUCTION}

One of the potentially useful assemblies for the study of ciliate-bacterial interactions is the two-stage cascade apparatus used in many experiments reported in the literature (e.g. Curds \& Cockburn, 1971; Jost et al., 1973; Ashby, 1976; Drake \& Tsuchiya, 1977; Swift et al., 1982). The upper chemostat of this assembly contains a pure bacterial culture, and it is operated at a dilution rate that is sufficiently low for the rate-limiting substrate to become essentially completely exhausted. The overflow of the bacterial chemostat feeds the lower chemostat containing the growing ciliates. The original objective in the use of the cascade apparatus was to study the dynamics of ciliate-bacterial interactions under steady-state conditions and without the complicating effects of bacterial growth. However, experimental work by Habte \& Alexander (1978) and Sambanis (1985) has shown, the first indirectly and the second directly, that bacterial growth cannot be eliminated. Indeed, in a mixed culture with ciliates, bacteria grow and reproduce on products of lysis and perhaps also metabolism of the ciliates in an interaction termed 'saprotrophy' (Sambanis, 1985). In spite of the occurrence of saprotrophy, common sense as well as mathematical models (see, e.g. Sambanis et al., 1987) suggest that the culture in the lower chemostat of a cascade should reach a steady state after some initial transients that last for no more than a week to $10 \mathrm{~d}$. However, experimental results reported in the literature for various pairs of micro-organisms do not agree on whether this actually occurs in practice.

Hamilton \& Preslan (1970) grew the ciliate Uronema sp. on a supply of non-growing Serratia marinorubra at dilution rates $(D)$ ranging from 0.029 to $0.14 \mathrm{~h}^{-1}$. They reported that the ciliates attained a steady state quickly in the chemostat and could, if necessary, be so maintained for weeks.' Jost et al. (1973) studied the interactions of Tetrahymena pyriformis and Azotobacter tinelandii in the lower chemostats of two cascades operated at $D=0.04 \mathrm{~h}^{-1}$ and $D=0.11 \mathrm{~h}^{-1}$. At both dilution rates, the population density of the ciliates became constant within

$†$ Present address: Department of Chemical Engineering, Massachusetts Institute of Technology, Cambridge, MA 02139 , USA. 
approximately one week. Swift et al. (1982) reported that in the lower chemostats of cascades containing $T$. pyriformis and Escherichia coli and operated at dilution rates ranging from 0.02 to $0.20 \mathrm{~h}^{-1}$, the population densities of ciliates and of all particles having roughly the same size as the bacteria did not vary systematically after one week of operation. However, the random changes which occurred were sometimes quite significant. On the other hand, Curds \& Cockburn (1971) found that a culture of $T$. pyriformis and Klebsiella aerogenes ( $K$. pneumoniae) fed with non-growing bacteria and operated at $D=0.254 \mathrm{~h}^{-1}$ did not reach steady state after $25 \mathrm{~d}$ operation. Instead, the various measured quantities exhibited significant unidirectional changes. With the similar system of $T$. pyriformis $-E$. coli interacting in the lower chemostat of a cascade at $D=0.04 \mathrm{~h}^{-1}$, Glaser (1984) observed slow changes (drifts) of the ciliate population density and mean cell volume and of the density of viable bacteria; the drifts lasted for more than $760 \mathrm{~h}$. During Ashby's (1976) experiment with the system Uronema marinum-Vibrio sp. at $D=0.014 \mathrm{~h}^{-1}$, the various measured quantities exhibited cycling variations as well as overall drifts. The culture did not reach steady state even after $100 \mathrm{~d}$ operation. Finally, Drake's (1975) data (some of which were also reported in Drake \& Tsuchiya, 1977) suggest a correlation which might exist between the occurrence of drifts in the lower chemostat of a cascade and the dilution rate at which that chemostat is operated. Indeed, uni-directional changes seem to have occurred at $D=0.023 \mathrm{~h}^{-1}$ and $D=0.060 \mathrm{~h}^{-1}$ but not at $D=0.125 \mathrm{~h}^{-1}$.

In the above reports of drifts, each of the measured quantities generally changed in the same direction in the various experiments. The ciliate population density increased and the ciliate mean cell volume decreased in all experiments except, perhaps, in the one reported by Ashby (1976). The concentration of ciliate biovolume (that is, the fraction of the culture volume occupied by the ciliate cells) remained constant or nearly constant in all experiments except that reported by Curds \& Cockburn (1971), in which the ciliate biovolume increased at an essentially constant rate until the termination of the culture after $25 \mathrm{~d}$ operation. The bacterial density in the ciliate chemostats generally decreased with time. Drake's (1975) experiments, however, revealed no unidirectional change of that quantity at any dilution rate.

In some of the experiments reported above, low-amplitude, long-period oscillations might have occurred as well. The overall changes of the measured quantities were, of course, the previously described long-term drifts. Thus, the cycling variations observed by Ashby (1976) could actually represent oscillations of either constant or slowly decreasing amplitude. Similarly, Glaser (1984) reported that the number of ciliate cells, the ciliate biovolume and the yield of ciliate biovolume on bacterial numbers seemed to exhibit damped oscillations with a period of $250-300 \mathrm{~h}$ and an amplitude equal to about $35 \%$ of the mean.

In experiments with the system $T$. pyriformis-E. coli, we too observed long-term drifts of the type described above. Some of these drifts persisted for more than 100 generations of ciliates, and produced a roughly twofold reduction in ciliate mean cell volume. We are not aware that similar phenomena occur with prokaryotic micro-organisms, and therefore they seemed worth investigating in more detail. This paper reports the results of the investigation. Its purposes were to (i) see if the drifts were artifacts produced by secular changes in the inputs to the chemostats or in the physical conditions of the chemostats, (ii) obtain an accurate quantitative description of the drifts, (iii) evaluate the effects of chemostat operating conditions on the rate and duration of the drifts, and (iv) conduct a preliminary study of the causes of the cellular and population changes that occur.

\section{METHODS}

Organisms. Tetrahymena pyriformis GL was supplied by Professor M. Gorovsky, Department of Biology, University of Rochester, NY, USA. This amicronucleate species should now probably be called simply $T$. pyriformis (Nanney \& McCoy, 1976). Escherichia coli B was provided by Professor J. T. Prince, Department of Microbiology, University of Minnesota. The organisms were maintained as described by Watson et al. (1981) except that the E. coli slants were stored at $7{ }^{\circ} \mathrm{C}$ instead of $9.9^{\circ} \mathrm{C}$.

Apparatus. All six experiments reported here were done with two-stage cascades of chemostats (cascades 1-6, respectively). The chemostats used were patterned after the design of Novick \& Szilard (1950). The cultures in the chemostats were maintained at constant temperature by circulating water from a bath maintained at $25 \pm 0.2^{\circ} \mathrm{C}$. 
(a)

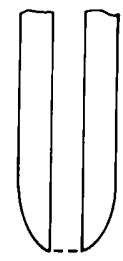

(b)

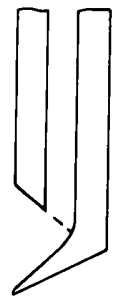

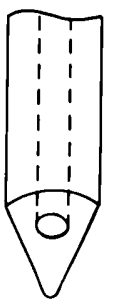

Fig. 1. The tips of the overflow lines of the chemostat vessels: $(a)$ the old tip; $(b)$ the new tip. The inside diameter of the capillary tubes is $2 \mathrm{~mm}$.

The lower chemostats of all six cascades had nominal volumes of $100 \mathrm{ml}$; this ensured constant surface-to-volume ratio and mixing and aeration patterns in the ciliate chemostats. The upper chemostats of cascades 1-4 had nominal volumes of $100 \mathrm{ml}$ and those of cascades 5 and 6 nominal volumes of $400 \mathrm{ml}$. The overflow siphon of the bacterial chemostat of cascade 1 had the tip shown in Fig. 1 (a) (old tip), whereas the siphons of the same chemostats of cascades 2-6 had the tip shown in Fig. $1(b)$ (new tip). The siphons of the ciliate chemostats had the old tip. Each ciliate chemostat was aerated with $1200 \mathrm{ml}$ (STP) atmospheric air $\mathrm{h}^{-1}$, and each $100 \mathrm{ml}$ bacterial chemostat with $2800 \mathrm{ml}(\mathrm{STP}) \mathrm{h}^{-1}$. Each $400 \mathrm{ml}$ bacterial chemostat was aerated with $5400 \mathrm{ml}^{(S T P)} \mathrm{h}^{-1}$ except during the first $50 \mathrm{~h}$ or so when the rate was $2800 \mathrm{ml}(\mathrm{STP}) \mathrm{h}^{-1}$. Before entering the cultures, the air was humidified and then sterilized by passage through two sterile tubular filters, the first of which contained glass wool and the second cotton wool.

Medium. The constituents of the medium (BC medium) fed to the upper chemostats of the cascades were autoclaved as four separate solutions to prevent any irreversible complexing. The solutions were mixed after they had cooled to room temperature. The composition of each solution (per litre of distilled water in the final medium) was as follows: (i) $0.335 \mathrm{~g} \mathrm{KH}_{2} \mathrm{PO}_{4}$ and $1.77 \mathrm{~g} \mathrm{~K}_{2} \mathrm{HPO}_{4}$; (ii) $1.25 \mathrm{~g}_{\left(\mathrm{NH}_{4}\right)_{2} \mathrm{SO}_{4}, 0.10 \mathrm{~g} \mathrm{MgSO}} .7 \mathrm{H}_{2} \mathrm{O}$ and I $\mathrm{mg}$ $\mathrm{Na}_{2} \mathrm{MoO}_{4} .2 \mathrm{H}_{2} \mathrm{O}$; (iii) $0.01 \mathrm{~g} \mathrm{NaCl}, 0.02 \mathrm{~g} \mathrm{CaCl}_{2}, 1 \mathrm{mg} \mathrm{FeCl} .6 \mathrm{H}_{2} \mathrm{O}$ and $2.8 \mathrm{mg} \mathrm{Na}$ (EDTA). 2 $\mathrm{H}_{2} \mathrm{O}$; and (iv) $0.5 \mathrm{~g}$ glucose. Each solution was sterilized by autoclaving at $121{ }^{\circ} \mathrm{C}$ for $20-60 \mathrm{~min}$, depending on its volume. Before autoclaving, each solution was filtered individually through a $0.45 \mu \mathrm{m}$ Millipore filter to remove the particles that increased the background count when electronically counting the bacteria and could also act as nuclei for the crystallization of precipitates in the medium.

Analyses. The population density and size distribution of $T$. pyriformis were obtained with an electronic particle counter and size distribution analyser [model $80 \mathrm{XY}$ Electrozone (Elzone) Celloscope, Particle Data Inc.]. The same instrument was used to measure the density and size distribution of small particles (bacteria + non-living particles of bacterial size). A $95 \mu \mathrm{m}$ aperture was used for the ciliates and a $30 \mu \mathrm{m}$ aperture for the small particles. The samples were diluted with a saline solution containing $8.5 \mathrm{~g} \mathrm{NaCl}$ and $0.2 \mathrm{~g} \mathrm{Na}_{2}$ (EDTA).2 $\mathrm{H}_{2} \mathrm{O}$ per litre of distilled water. To reduce the background count, the diluting solution was filtered continuously through a series of two $0.22 \mu \mathrm{m}$ Ultipore filters (Pall Trinity Micro Corporation) before use. The dilutions were such that the ciliate count was between $6 \times 10^{2}$ and $5 \times 10^{3}$ with a sampling volume of $501.9 \mu$ and the small particle count between $1.5 \times 10^{4}$ and $4 \times 10^{4}$ with a sampling volume of $100 \mu$. The density of viable $E$. coli was measured by preparing spread plates on tryptone/glucose/yeast extract agar medium after appropriate dilution of the samples with sterile saline. Samples from pure $E$. coli cultures produced equal (within statistical error) Elzone and viable counts, indicating that essentially all plated $E$. coli cells developed into colonies.

Inoculation procedure. The $E$. coli cells used to inoculate the bacterial chemostats were grown in batch culture in a medium very similar to BC (preculture BC medium). Ciliate inocula were taken from two different sources, either adapted to axenic growth or adapted to monoxenic growth on $E$. coli. Each of the ciliate chemostats of cascades 1 and 2 was inoculated with approximately $50 \mathrm{ml} T$. pyriformis preculture in proteose peptone/yeast extract (PPYE) broth, plus approximately $50 \mathrm{ml}$ preculture $\mathrm{BC}$ solution without glucose. This solution reduced the foaming of PPYE and initiated an adaptation of $T$. pyriformis to the medium in which $E$. coli was growing. The ciliate chemostats of cascades 3-6 were all inoculated from the same microbial suspension which was prepared as follows. A two-stage cascade, both chemostats of which had nominal volumes of $100 \mathrm{ml}$, was started with a $T$. pyriformis preculture in PPYE in the second stage and $E$. coli in the first stage. The chemostats were fed with BC medium and operated at $D=0.03 \mathrm{~h}^{-1}$ for $10 \mathrm{~d}$; then the culture in the lower stage was harvested and diluted with $500 \mathrm{ml} \mathrm{BC}$ medium without glucose. The suspension was homogenized and used to fill the lower chemostats of cascades 3-6.

Sampling procedure. To minimize the disturbance of the cultures caused by the withdrawal of samples (approx. $8 \mathrm{ml}$ ), all counts and size distributions were each time taken from a single sample and a period of 2-4 d was allowed to elapse before a chemostat was sampled again. The sampling intervals of cascades 3-6 were 2,3 , or $4 \mathrm{~d}$, and each sampling interval of each of these chemostats was chosen at random, with equal probability being assigned to each 
of the three choices. This rule also applied to cascade 2 before the increase in medium flow rate: after that, cascade 2 was sampled every $2 \mathrm{~d}$ and at the end every $3 \mathrm{~d}$. The lower chemostat of each cascade was sampled first and the upper second. To prevent the sudden discharge of bacterial culture, the overflow siphons of the upper chemostats of cascades 2-6 were broken just before sampling the lower chemostats; they were restored immediately after sampling. That practice was not followed with cascade 1. After the withdrawal of a sample, the initial dilutions for all counts were completed within 4 min or less, and then the counts and size distributions were taken, one at a time, after completing any necessary additional dilutions. Tests (Sambanis, 1985) showed that the counts and size distributions thus obtained were representative of the cultures at the time of sampling.

Development of the experimental technique. Certain aspects of the technique described above were modifications of the techniques used by Watson et al. (1981) and Swift et al. (1982). Those modifications were made because of problems caused by the existing techniques during initial cascade experiments: (1) after a few (usually 3-4) days of operation of the cascades, macroscopic biofilms and flocs developed in the bacterial chemostats: (2) the E. coli density in the bacterial chemostats exhibited a strong downward drift; (3) an iron precipitate developed on the bottom of the medium jugs, and that precipitate failed to enter the chemostats; (4) there was significant scatter in the data on the density of viable bacteria in the ciliate chemostats.

Problems 1, 2 and 3 were found to be associated with aspects of the medium composition. To alleviate them, the medium of Watson et al. (1981) was modified as follows: (i) the concentration of glucose was reduced to $0 \cdot 5 \mathrm{~g} \mathrm{l}^{-1}$; (ii) all iron was added in the ferric instead of the ferrous form; (iii) the amount of $\mathrm{Na}_{2}(\mathrm{EDTA}) .2 \mathrm{H}_{2} \mathrm{O}$ was increased to twice that stoichiometrically needed to chelate all the iron. The medium which resulted from these changes is the BC medium described above. Furthermore, to ensure that the bacterial growth rate was limited by glucose, the bacterial chemostats were always operated a low dilution rate of approximately $0.03 \mathrm{~h}^{-1}$. [An analysis of the effect of the dilution rate on the identity of the rate-limiting substrate is given by Sambanis (1985) and Baltzis \& Fredrickson (1987).] After the above changes were made, no macroscopic biofilms or flocs of biomaterial were apparent in the bacterial chemostats. Furthermore, no precipitate was ever observed on the bottom of the medium jugs, and the downward drift of the bacterial density was drastically reduced. For example, in a bacterial chemostat operated at $D=0.03 \mathrm{~h}^{-1}$, the density of viable $E$. coli fell to $40 \%$ of the maximum value after $10 \mathrm{~d}$ operation and to $80 \%$ of the maximum value after $33 \mathrm{~d}$ operation when $\mathrm{BC}$ medium contained $\mathrm{Na}_{2}$ (EDTA). $2 \mathrm{H}_{2} \mathrm{O}$ at $0.4 \mathrm{mg} \mathrm{l}^{-1}$ and $2.8 \mathrm{mg}^{-1}$ respectively.

Problem 4 was found to be associated with the irregular operation of overflow siphons having the tip design shown in Fig. 1 (a) (Tunkel, 1983). In particular, those siphons would deliver as many as 15 to 20 drops at a time corresponding to about $1 \mathrm{ml}$ culture - followed by a long period of zero overflow. With the bacterial densities used, it can be calculated that the irregular operation of a siphon would cause the density of viable $E$. coli in the ciliate chemostat to vary by a factor of 10 or more. Thus, if the lower chemostat were sampled at random times relative to the discharge of the overflow, the scatter in the viable counts would be very significant. Such a scatter was reported by Swift et al. (1982), and although those authors attributed it to other factors, it seems that in that case also the scatter was caused by the irregular operation of the overflow. The operation of the siphons was improved by adopting the tip design shown in Fig. 1 (b) (suggested by D. P. Lavin - personal communication), which gave a constant rate of discharge. For example, for a $100 \mathrm{ml}$ bacterial chemostat fed with $3.2 \mathrm{ml} \mathrm{BC}$ medium h h $^{-1}$, the standard deviation of the intervals between drops was $24 \%$ of the mean. The volume of a typical drop remained approximately $0.06 \mathrm{ml}$, so that the density of viable bacteria in a ciliate chemostat was expected to vary by a factor of 1.6 or less.

\section{RESULTS}

Figs 2-4 show the results obtained during experiments with cascades 1-6: the quantities presented are as follows. $N_{\mathrm{T}}$ is the population density of $T$. pyriformis and $\bar{v}_{\mathrm{T}}$ is the mean cell volume of the ciliate cells; $N_{\mathrm{T}} \bar{v}_{\mathrm{T}}$ is thus the concentration of ciliate biovolume. $N_{\mathrm{E}_{2}}$ and $N_{\mathrm{sp}_{2}}$ are the densities of viable $E$. coli and of small particles, respectively, in the ciliate chemostats, and $N_{\mathrm{E}_{1}}$ and $N_{\mathrm{sp}_{1}}$ are the same quantities in the bacterial chemostats. $Q$ is the volumetric flow rate of medium into the cascades, and $\Delta Q$ represents a step increase in $Q$. Table 1 reports the dilution rate at which each chemostat was operated. Arrows $f_{1}$ and $f_{2}$ in Figs 3 and 4 show the times at which the culture in the lower chemostat of a cascade was harvested and filtered aseptically through a $0.45 \mu \mathrm{m}$ filter. The filters withheld all organisms, and the sterile filtrates thus obtained were inoculated with $E$. coli to measure the amount of bacterial growth supported by each solution.

Fig. 2 shows the results obtained during cascade experiments 1 and 2 . To ensure that all data were collected with ciliates well adapted to monoxenic growth, the cascades were operated for at least a week prior to the withdrawal of the first samples. In the bacterial chemostat of cascade 2 , 


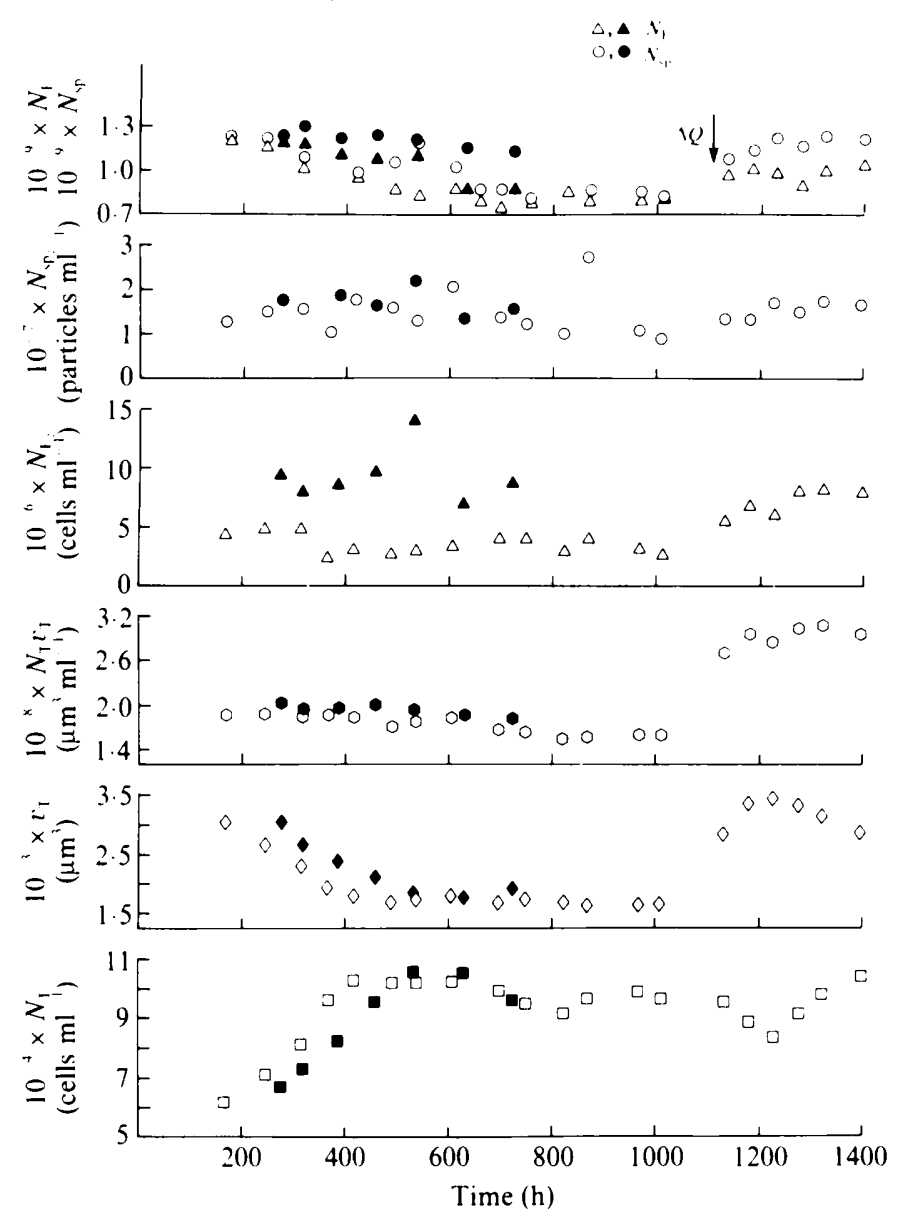

Fig. 2. Results obtained during cascade experiments 1 (filled symbols) and 2 (open symbols).

Table 1. Dilution rates $\left(h^{-1}\right)$ at which the upper and lower chemostats of cascades 1-6 were operated

$\begin{array}{lcc}\text { Cascade no. } & \text { Upper chemostat } & \text { Lower chemostat } \\ 1 & 0.033 & 0.033 \\ 2 \text { before } \Delta Q & 0.034 & 0.033 \\ 2 \text { after } \Delta Q & 0.115 & 0.109 \\ 3 & 0.036 & 0.037 \\ 4 & 0.035 & 0.037 \\ 5 & 0.031 & 0.116 \\ 6 & 0.032 & 0.121\end{array}$

$N_{\mathrm{E}_{1}}$ and $N_{\mathrm{sp}}$ drifted slowly downwards until about $700 \mathrm{~h}$, and then remained constant until the step increase in medium flow rate, $\Delta Q$. After $\Delta Q, N_{\mathrm{E}_{1}}$ and $N_{\mathrm{sp}_{1}}$ increased, indicating that maintenance is important to a pure culture of $E$. coli at the low dilution rates used. In the ciliate chemostat of cascade 2 before $\Lambda Q$, the measured quantities behaved as follows. Between 170 and $420 \mathrm{~h}, N_{\mathrm{T}}$ increased and $\bar{v}_{\mathrm{T}}$ decreased in an essentially linear fashion. After $420 \mathrm{~h}$, both quantities remained nearly constant except for a decrease in $N_{\mathrm{T}}$ around $800 \mathrm{~h} . N_{\mathrm{T}} \bar{v}_{\mathrm{T}}$ exhibited a very slow downward drift, apparently as a result of the downward drift of $N_{\mathrm{E}_{1}} \cdot N_{\mathrm{E}_{2}}$ decreased slightly around $350 \mathrm{~h}$, followed by a very slow upward drift. The data on $N_{\mathrm{sp}_{2}}$ revealed no 


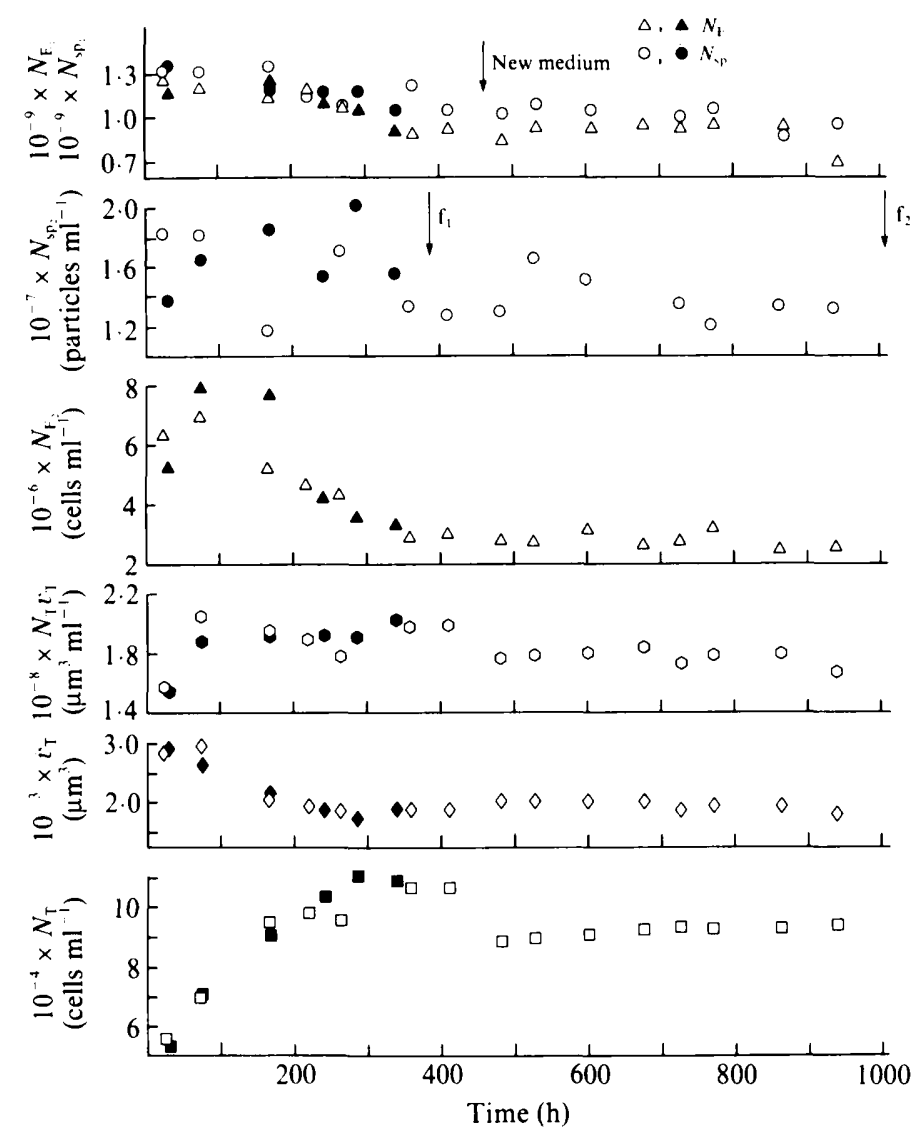

Fig. 3. Results obtained during cascade experiments 3 (open symbols) and 4 (filled symbols).

unidirectional change; however, they were considerably scattered, possibly because of smallamplitude oscillations having a period of $200-250 \mathrm{~h}$. After $\Delta Q, N_{\mathrm{T}}$ decreased and then started to drift upwards whereas $\bar{v}_{\mathrm{T}}$ increased and then started to drift downwards. $N_{\mathrm{T}} \bar{v}_{\mathrm{T}}$ approximately doubled, as did $N_{\mathrm{E}_{2}}$, but $N_{\mathrm{sp}_{2}}$ was not affected significantly by $\Delta Q$.

The data on $N_{\mathrm{E}_{1}}, N_{\mathrm{sp}_{1}}, N_{\mathrm{T}} \bar{v}_{\mathrm{T}}$ and $N_{\mathrm{sp}_{2}}$ from cascade 1 compared well with those from cascade 2. However, the data on $N_{\mathrm{T}}$ and $\bar{v}_{\mathrm{T}}$ from cascade 1 were shifted to later times by $3 \mathrm{~d}$ relative to those from cascade 2 . That shift was probably the result of the older (by approximately $3 \mathrm{~d}$ ) axenic ciliate culture used to inoculate cascade 2 relative to that used to inoculate cascade 1 . The values of $N_{E_{2}}$ measured during cascade experiment 1 were two to three times those measured during cascade experiment 2 . That difference was caused by the discharge of bacterial culture which occurred when the ciliate chemostat of cascade 1 was sampled.

During cascade experiment 3 (Fig. 3), $N_{\mathrm{E}_{1}}$ and $N_{\mathrm{sp}_{1}}$ exhibited downward drifts very similar to those seen during cascade experiments 1 and 2 . In the ciliate chemostat of cascade 3 , the populations underwent initial transients, manifested as initial increases of $\bar{v}_{\mathrm{T}}, N_{\mathrm{T}} \bar{v}_{\mathrm{T}}$ and $N_{\mathrm{E}_{2}}$, that lasted for approximately $80 \mathrm{~h} . N_{\mathrm{T}}$ increased until about $400 \mathrm{~h}$ and then stabilized at a value smaller than that at the end of the upward drift. $\bar{v}_{\mathrm{T}}$ decreased until $260 \mathrm{~h}$ and remained constant thereafter. $N_{\mathrm{T}} \bar{v}_{\mathrm{T}}$ remained essentially constant except for a small decrease around $450 \mathrm{~h} . N_{\mathrm{E}_{2}}$ declined until $360 \mathrm{~h}$ and remained constant thereafter. The data on $N_{\mathrm{sp}}$, were significantly scattered, but revealed no unidirectional change. The scatter in the data on $N_{\mathrm{sp}_{2}}$ and $N_{\mathrm{T}} \bar{v}_{\mathrm{T}}$ could have been the result of small-amplitude oscillations.

The data from cascade 4 reproduced well those from cascade 3 during the time that the former cascade was operated. Operation of cascade 4 was terminated at the time indicated by arrow $f_{1}$ 
Table 2. Amounts of E. coli growth supported by filtrates F3, F4, F5 and F6

F3 = filtrate from cascade 3 , etc. $N_{\mathrm{E}}$ and $N_{\mathrm{E}_{\mathrm{f}}}$ are the population densities of viable bacteria at the beginning and during the stationary phase of each test culture, respectively.

\begin{tabular}{|c|c|c|c|}
\hline Filtrate & $\begin{array}{l}10^{-2} \times N_{\mathrm{E}_{\mathrm{i}}} \\
\left(\text { cells } \mathrm{ml}^{-1}\right)\end{array}$ & $\begin{array}{l}10^{-7} \times N_{\mathrm{E}_{\mathrm{f}}} \\
\text { (cells } \mathrm{ml}^{-1} \text { ) }\end{array}$ & $\begin{array}{c}\text { Bacterial growth } \\
{\left[10^{-7} \times\left(N_{\mathrm{E}_{\mathrm{f}}}-N_{\mathrm{E}_{\mathrm{r}}}\right)\right.} \\
\left.(\text { cells ml })^{-1}\right]\end{array}$ \\
\hline F3 & 6.56 & 2.82 & $2 \cdot 82$ \\
\hline $\mathrm{F} 4$ & 7.73 & 3.49 & 3.49 \\
\hline F5 & 7.09 & 2.85 & $2 \cdot 85$ \\
\hline F6 & 8.45 & 3.40 & 3.40 \\
\hline
\end{tabular}

Table 3. Mean rates of change (calculated by the least-squares method) of the ciliate population density and mean cell volume during the long-term drifts in three cascade experiments

\begin{tabular}{|c|c|c|c|c|c|c|}
\hline \multirow[b]{2}{*}{$\begin{array}{c}\text { Cascade } \\
\text { expt }\end{array}$} & \multirow{2}{*}{$\begin{array}{l}\text { Ciliate inoculum } \\
\text { adapted or } \\
\text { non-adapted to } \\
\text { monoxenic growth }\end{array}$} & \multirow{2}{*}{$\begin{array}{l}\text { Dilution } \\
\text { rate of } \\
\text { ciliate } \\
\text { chemostat } \\
\left(\mathrm{h}^{-1}\right)\end{array}$} & \multicolumn{2}{|c|}{$\begin{array}{l}\text { Mean rate of } \\
\text { increase of } N_{\mathrm{T}}\end{array}$} & \multicolumn{2}{|c|}{$\begin{array}{l}\text { Mean rate of } \\
\text { decrease of } \bar{v}_{\mathrm{T}}\end{array}$} \\
\hline & & & (cells $\mathrm{ml}^{-1} \mathrm{~h}^{-1}$ ) & $\begin{array}{c}\text { (cells } \mathrm{ml}^{-1} \\
\text { per generation) }\end{array}$ & $\left(\mu m^{3} h^{-1}\right)$ & $\begin{array}{c}\left(\mu \mathrm{m}^{3} \text { per }\right. \\
\text { generation) }\end{array}$ \\
\hline 2 & Non-adapted & 0.033 & 170 & 3570 & $5 \cdot 18$ & 109 \\
\hline 4 & Adapted & 0.037 & 185 & 3470 & $4 \cdot 36$ & $81 \cdot 7$ \\
\hline 5 & Adapted & $0 \cdot 116$ & 76.7 & 458 & 3.59 & $21 \cdot 5$ \\
\hline
\end{tabular}

in Fig. 3; the culture in the ciliate chemostat was then filtered and the resulting broth (filtrate F4) was tested for its ability to support bacterial growth. The ciliate culture of cascade 3 was filtered at the time indicated by arrow $f_{2}$, yielding filtrate F3. Amounts of bacterial growth supported by the filtrates are reported in Table 2 .

Data from cascades 5 and 6 are shown in Fig. 4 . In the bacterial chemostat of cascade $5, N_{\mathrm{E}_{1}}$ and $N_{\mathrm{sp}_{1}}$ exhibited an initial increase but then drifted slowly downwards and later stabilized as in the bacterial chemostats of cascades 1-4. In the ciliate chemostat of cascade $5, \bar{v}_{\mathrm{T}}, N_{\mathrm{T}} \bar{v}_{\mathrm{T}}, N_{\mathrm{E}_{2}}$ and $N_{\mathrm{sp}_{2}}$ underwent initial transient increases. The upward drift of $N_{\mathrm{T}}$ and the downward drift of $\bar{v}_{\mathrm{T}}$ lasted until about $600 \mathrm{~h}$. After the initial increase, $N_{\mathrm{E}_{2}}$ exhibited a downward drift until about $500 \mathrm{~h} ; N_{\mathrm{sp}_{2}}$ also appeared to exhibit a very slow downward drift. $N_{\mathrm{T}} \bar{v}_{\mathrm{T}}$ exhibited apparent sustained oscillations with an amplitude of approximately $20 \%$ of the mean and a period of about $300 \mathrm{~h}$.

The data on $N_{\mathrm{E}_{1}}, N_{\mathrm{sp}_{1}}, N_{\mathrm{T}} \bar{v}_{\mathrm{T}}, \bar{v}_{\mathrm{T}}$ and $N_{\mathrm{T}}$ from cascade 6 compared well with those from cascade 5. The data on $N_{\mathrm{E}_{2}}$ and $N_{\mathrm{sp}_{2}}$ from the two cascades also compared well, except for the points around $300 \mathrm{~h}$. Those differences, being only temporary, can be considered as of no particular significance.

At the times indicated by arrows $f_{1}$ and $f_{2}$ in Fig. 4, cascades 6 and 5 were terminated and sterile filtrates F6 and F5, respectively, were prepared. The amounts of $E$. coli growth supported by these filtrates are reported in Table 2 .

Table 3 summarizes the mean rates (calculated by the least-squares method) of increase of $N_{\mathrm{T}}$ and decrease of $\bar{v}_{\mathrm{T}}$ during the long-term drifts in the ciliate chemostats of cascades 2,4 and 5 . The time of a generation used to calculate the data was defined as $\ln 2 / D$.

\section{DISCUSSION}

In all the experiments described above, the cultures in the ciliate chemostats exhibited long drifts but eventually attained steady states. Similarly, the population densities of viable bacteria and small particles in the upper chemostats become essentially constant after a long time period of slow downward drift. This section discusses the changes observed in the chemostats before the establishment of steady states, and discusses and compares the behaviour of the ciliate chemostats under steady-state conditions. Finally, it gives some speculations on the mechanisms that might be producing the observed results. 


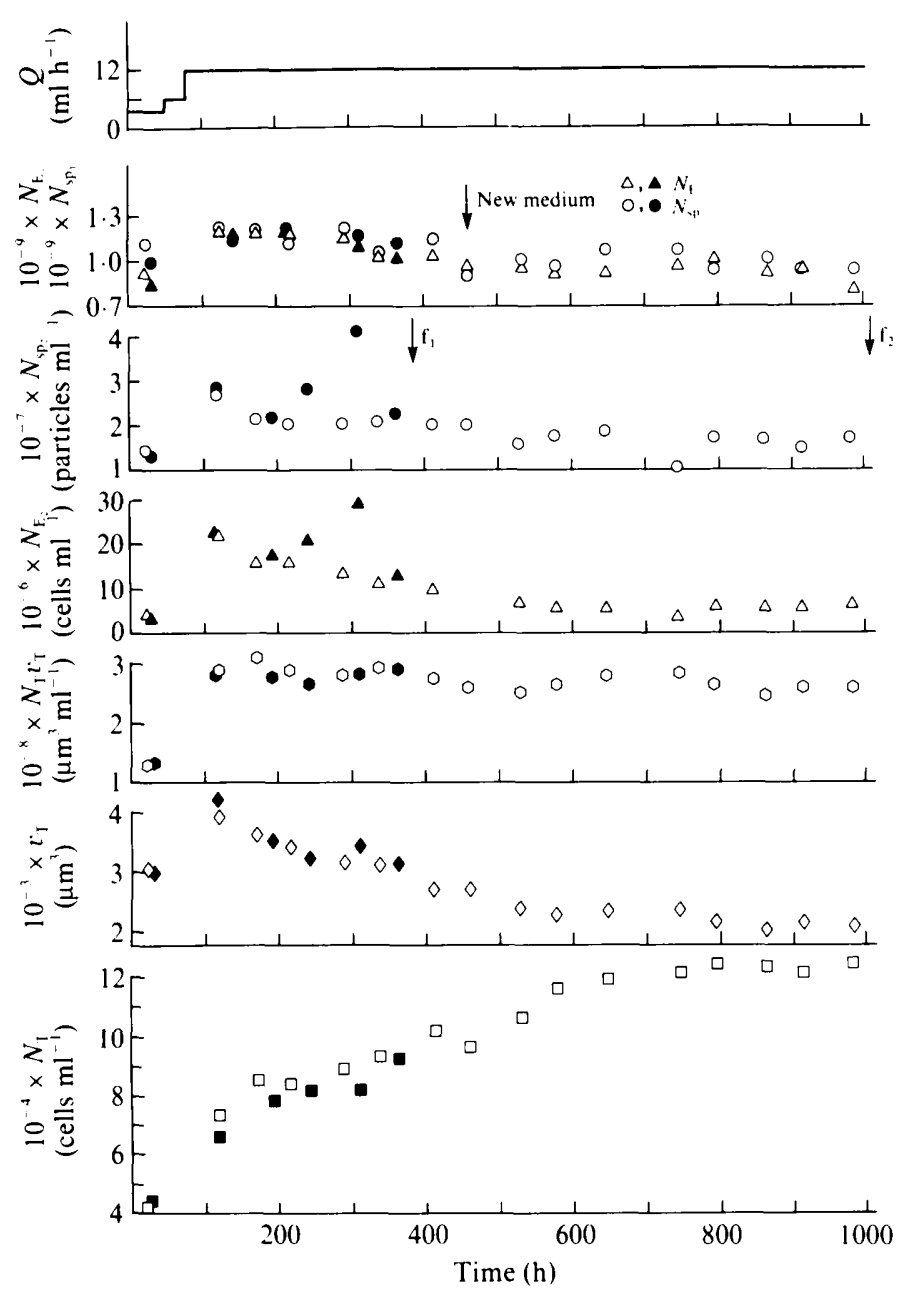

Fig. 4. Results obtained during cascade experiments 5 (open symbols) and 6 (filled symbols).

\section{Long-term drifts}

The downward drifts of bacterial density in the bacterial chemostats of cascades 1-6 lasted for at least $400 \mathrm{~h}$ (about 19 generations). These drifts were too small to affect significantly the dynamics of the ciliate chemostats, so they can be ignored in studies of the type reported here. The causes of the downward drifts are not clear, however. Perhaps BC medium deteriorates slowly with time, but a biological factor of the bacterial population may also be involved. Downward drifts of the density of $E$. coli EO2512 (a derivative of strain K 12) were also observed by Glaser (1984) in chemostats operated at low dilution rates (about $0.04 \mathrm{~h}^{-1}$ ). Those drifts were significantly more intense than those reported here, and it seems that their primary cause was the use of the iron-deficient medium of Watson et al. (1981), although Glaser attributed them to other factors. The initial increases of $N_{\mathrm{E}_{1}}$ and $N_{\mathrm{sp}_{1}}$ in the bacterial chemostats of cascades 5 and 6 were due either to the maintenance requirement of $E$. coli, to the oxygen limitation of the cultures when the first sets of data points were collected, or to both of those factors.

In the ciliate chemostats, the direction of drift of each measured quantity was the same in all experiments. Thus, $N_{\mathrm{T}}$ increased and $\bar{v}_{\mathrm{T}}$ decreased with time, in agreement with the observations of Curds \& Cockburn (1971) and Glaser (1984). In the chemostats operated at low dilution rates, $N_{\mathrm{T}}$ reached its steady-state value after an overshoot. The ciliate biovolume 


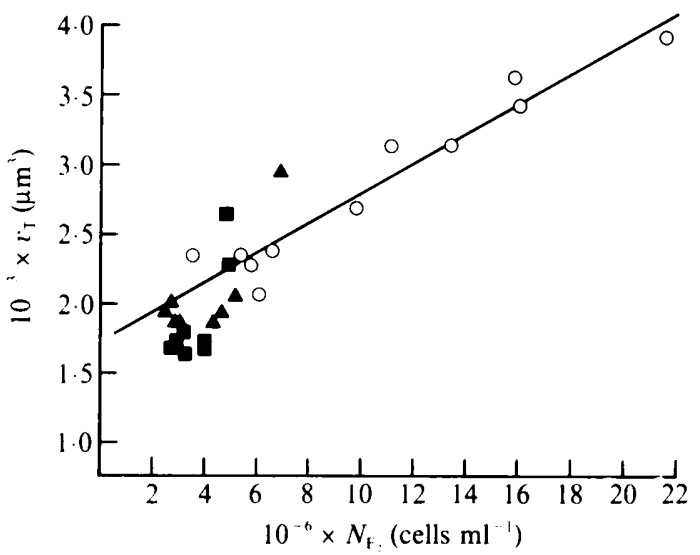

Fig. 5. Relationship between $T$. pyriformis mean cell volume $\left(\bar{v}_{\mathrm{T}}\right)$ and the population density of viable $E$. coli $\left(N_{\mathrm{E}}\right)$ as expressed by the data in Figs $2-4$. $\bigcirc$, Points from cascade experiment $5 ; \boldsymbol{\Delta}$, points from cascade experiment $3 ; \boldsymbol{\square}$, points from cascade experiment 2 . The straight line is the least-squares fit of the data from cascade 5

concentration remained essentially constant, as was observed by Glaser (1984), but not by Curds \& Cockburn (1971). In cascade experiments 3-6, $N_{\mathrm{E}_{2}}$ and $N_{\mathrm{sp}_{2}}$ decreased with time; the bacterial density also decreased in the experiments of Curds \& Cockburn (1971), Ashby (1976) and Glaser (1984), but not in the experiments of Drake (1975). As seen from Figs 2-4 and Table 3, the rates of change during the drifts and the duration of the drifts depend on the dilution rate, but apparently not on the state of the cells in the ciliate inoculum (ciliates adapted or non-adapted to monoxenic growth). The drifts last longer but the rates of change become smaller as the dilution rate is increased. Thus, the ciliate chemostats of cascades $1-3$ reached steady state within $500 \mathrm{~h}$ ( 25 generations) or less, whereas it took $800 \mathrm{~h}$ (125 generations) for the ciliate chemostat of cascade 5 to reach steady state. Filtrates of chemostat cultures from cascades 4 and 6 , which were collected at times indicated by $f_{1}$ in Figs 3 and 4, supported roughly the same amounts of bacterial growth. Similarly, filtrates of chemostat cultures 3 and 5, which were collected at times indicated by $f_{2}$ in Figs 3 and 4 , supported the same amounts of bacterial growth, but these were substantially less than the amounts supported by broths from cascades 4 and 6 . Hence, the amount of bacterial growth supported by the abiotic phase of a ciliate chemostat decreases with time, and does not seem to depend on the dilution rate at which the chemostat is operated.

At a lower trophic level, the equivalent of the decrease in $N_{\mathrm{E}_{2}}$ would be that of a decrease in the concentration of the rate-limiting substrate in a chemostat containing a pure bacterial culture. Indeed, during the long-term continuous cultivation of Cytophaga johnsonae, Höfle (1983) observed stepwise decreases of the concentration of glucose (the rate-limiting nutrient). Unfortunately, Höfle did not measure any parameters of the bacterial population other than the concentration of its biomass, so it is not known whether that population underwent changes similar to the ones reported here for the ciliate population.

The results of the short-term experiments of Swift (1981) (some of which were also reported in Swift et al., 1982) indicated the existence of a positive and in fact almost linear correlation between $\bar{v}_{\mathrm{T}}$ and $N_{\mathrm{E}_{2}}$. The data from the present experiments also indicate the existence of such a correlation (Fig. 5). The points which reveal the correlation best are from cascade experiment 5 , whereas the points from the low-dilution-rate experiments 2 and 3 are clustered in the lower left corner of the diagram. What is cause and what is effect here is not clear, but the correlation is certainly consistent with the view that the ciliate population is a more effective scavenger of bacteria when its biomass is distributed among many small cells rather than among a few large cells (Fenchel, 1980).

The facts that (i) long-term drifts were reported by several investigators and for various ciliates and (ii) each measured quantity generally drifted in the same direction in the reported 
Table 4. Values of the yield coefficient $X_{\mathrm{N}}\left[=\left(N_{\mathrm{T}} \overline{\mathrm{T}} \mathrm{T}\right) /\left(N_{\mathrm{E}_{1}}-N_{\mathrm{E}_{2}}\right)\right]$ calculated from the steadystate data of cascade experiments 2, 3 and 5

The reported values of $N_{\mathrm{T}} \bar{v}_{\mathrm{T}}, N_{\mathrm{E}}$ and $N_{\mathrm{E}}$, are the mean values of these quantities during the time periods considered.

$\begin{array}{ccccccc}\text { Cascade } & \begin{array}{c}\text { Dilution rate } \\ \text { of ciliate } \\ \text { expt } \\ \left(\mathrm{h}^{-1}\right)\end{array} & \begin{array}{c}\text { Timestat } \\ \text { considered }\end{array} & \begin{array}{c}10^{-8} \times N_{\mathrm{T}} \overline{\mathrm{T}}_{\mathrm{T}} \\ \left(\mu \mathrm{m}^{3} \mathrm{ml}^{-1}\right)\end{array} & \begin{array}{c}10^{-8} \times N_{\mathrm{E}_{1}} \\ (\text { cells ml }\end{array} & \begin{array}{c}10^{-6} \times N_{\mathrm{E}_{2}} \\ \left(\text { cells } \mathrm{ml}^{-1}\right)\end{array} & \begin{array}{c}X_{\mathrm{N}} \\ \left(\mu \mathrm{m}^{3} \text { per cell }\right)\end{array} \\ 2 & 0.033 & \begin{array}{l}650 \mathrm{~h}-\Delta Q \\ 3\end{array} & 1.603 & 7.951 & 3.605 & 0.20 \\ 5 & 0.037 & \begin{array}{c}480-600 \mathrm{~h} \\ 450-900 \mathrm{~h}\end{array} & 1.785 & 9.117 & 2.798 & 0.20 \\ & 0.116 & \begin{array}{l}700-1000 \mathrm{~h} \\ 700-950 \mathrm{~h}\end{array} & 2.618 & & 5.357 & 0.27\end{array}$

experiments, suggest that the long-term drifts are not experimental artifacts caused by such factors as slow deterioration of the medium fed to the cascade, by gradual accumulation of biologically active chemicals unknowingly added with the sparging air or leached from the chemostat vessels, or by slow changes in the conditions of the chemostat walls. Rather, we conclude that the drifts represent the ciliates' response to being placed in an environment with which they are not quite in biological equilibrium.

The observed changes in the ciliate population seem to be physiological rather than genetic in nature. In an attempt to investigate the type of change, Glaser (1984) conducted a number of test batch cultures of $T$. pyriformis on $E$. coli with ciliate and bacterial strains isolated from chemostats after $2230 \mathrm{~h}$ operation and with strains from stock cultures. The growth rates, yields, and maximum and minimum sizes reached in batch growth were not significantly different for the chemostat and stock strains, and the author concluded that the drifts he observed were probably not reflections of changes in the genotypes of the ciliates. The results shown in Fig. 2 of the present paper support this conclusion. Disturbance of the steady state by increase of the medium flow rate in cascade 2 led to a fairly rapid increase in the mean volume of the ciliate cells in response to the increased food availability that accompanied the disturbance. When this response was complete, the ciliate population characteristics resumed the drifts they had exhibited in the initial stage of the experiment: downward for $\bar{v}_{\mathrm{T}}$ and upward for $N_{\mathrm{T}}$.

\section{Steady-state chemostats}

At steady state, the densities of viable bacteria in the ciliate chemostats of cascades 1-6 were higher in the chemostats operated at the higher dilution rate. The ciliate density and mean cell volume and the density of small particles also increased with dilution rate but by smaller amounts. According to the short-term experiments of Swift (1981), $\bar{v}_{\mathrm{T}}, N_{\mathrm{E}_{2}}$ and $N_{\mathrm{sp}_{2}}$ correlate positively but $N_{\mathrm{T}}$ negatively with $D$. The discord between the present results and those of Swift (1981) must be due to the fact that the latter data were collected before steady states were reached.

The yields of ciliate biovolume on bacterial numbers, $X_{\mathrm{N}}$ and on bacterial biovolume, $X_{\mathrm{V}}$, are defined as follows:

$$
X_{\mathrm{N}}=\frac{N_{\mathrm{T}} \bar{v}_{\mathrm{T}}}{N_{\mathrm{E}_{1}}-N_{\mathrm{E}_{2}}} \text { and } X_{\mathrm{V}}=\frac{N_{\mathrm{T}} \bar{v}_{\mathrm{T}}}{\left(\bar{v}_{\mathrm{E}}\right)\left(N_{\mathrm{E}_{1}}-N_{\mathrm{E}_{2}}\right)}
$$

where $\bar{v}_{\mathrm{E}}$ is the mean volume of viable $E$. coli cells. The values of $X_{\mathrm{N}}$ obtained using the sı $\lrcorner$ dystate data from cascades 2,3 , and 5 are reported in Table 4 . One sees that $X_{\mathrm{N}}$ increases with $D$, in agreement with the results of Swift et al. (1982). As explained in that paper, the positive correlation between $X_{\mathrm{N}}$ and $D$ seems to be due to a higher water content of rapidly growing ciliate cells relative to slowly growing ones and not to a strong maintenance requirement of $T$. pyriformis. This view is also supported by the fact that $X_{\mathrm{V}}$ during experiment 5 was greater than 1 , since the average volume of $E$. coli cells in the overflows from the bacterial chemostats was $0 \cdot 19-0 \cdot 22 \mu \mathrm{m}^{3}$. Values of $X_{\mathrm{V}}$ well above 1 were also reported by Swift et al. (1982), especially at high dilution rates. 


\section{Speculations}

The drift phenomena reported here may be a consequence of the peculiar genetic organization and mode of regulating cell cycle events of ciliates, which have recently been reviewed by Berger (1984). Almost all ciliate cell function (presumably all such function in the case of amicronucleate species like $T$. pyriformis) is controlled by a polygenomic macronucleus. Division of the macronucleus is amitotic, and therefore the distribution of macronuclear DNA between sister cells shows significant random deviations from an even split. Cell mass, like macronuclear DNA, is partitioned between sister cells with some randomness and is strongly correlated with macronuclear DNA content. Thus, variations in macronuclear DNA content and cell mass are introduced continually by divisions of ciliates, and one infers that these variations of phenotype should have some persistence from generation to generation. If such variations are correlated with variations in cell generation time, then the selective pressure of chemostat washout might well produce drifts in cell size of the type reported in this paper. For example, the low food availability in a chemostat might cause smaller cells to reproduce slightly more rapidly than large cells, resulting in selection of the smaller cells. The effects of chemostat dilution rate also seem explicable on such a basis. Decrease of chemostat dilution rate causes a decrease in food availability, and this in turn may be expected to increase the intensity of the selection pressure exerted by the chemostat.

Some results obtained with the ciliate Didinum nasutum suggest that the foregoing explanation of drifts may be too simple. Salt (1975) observed that the mean volume of cells in synchronously dividing clones of this organism drifted upward in experiments in which food (Paramecium) availability was maintained at high levels by periodic replenishments, and no D. nasutum cells were removed from the cultures. Clearly, selection cannot be invoked to explain such results, and it seems likely that the principal, even if not the only, effect producing the observed drift was that each cell more than doubled its size during its complete cell cycle. Did the $T$. pyriformis cells during the drifts reported here increase their size by less than a factor of two during their complete cell cycles? We cannot say. Evidently, experiments in which food availability can be held at high levels as well as low ones, and in which selection can be turned on or off, need to be done to resolve these questions.

This research was supported in part by the National Science Foundation, Grant no. CPE-8020783, and by the Graduate School of the University of Minnesota; we are grateful for this support. Discussions with Drs Friedrich Srienc and David Glaser were most helpful to us, also.

\section{REFERENCES}

AsHBy, R. E. (1976). Long-term variations in a protozoan chemostat culture. Journal of Experimental Marine Biology and Ecology 24, 227-235.

Baltzis, B. C. \& Fredrickson, A. G. (1987). Limitations of growth rate by two complementary nutrients: some elementary but neglected considerations. Biotechnology and Bioengineering (in the Press).

BERGER, J. D. (1984). The ciliate cell cycle. In The Microbial Cell Cycle, pp. 191-208. Edited by P. Nurse \& E. Streiblová. Boca Raton, Florida CRC Press.

Curds, C. R. \& Cockburn, A. (1971). Continuous monoxenic culture of Tetrahymena pyriformis. Journal of General Microbiology 66, 95-108.

DRAKE, J. F. (1975). Effect of the environment on microbial prey-predator interactions. $\mathrm{PhD}$ thesis, University of Minnesota, Minneapolis.

Drake, J. F. \& Tsuchiya, H. M. (1977). Growth kinetics of Colpoda steinii on Escherichia coli. Applied and Environmental Microbiology 34, 18-22.

FenChel, T. (1980). Suspension feeding in ciliated protozoa: feeding rates and their ecological significance. Microbial Ecology 6, 13-25.
GLASER, D. (1984). Continuous culture experiments with Tetrahymena pyriformis and Escherichia coli. PhD thesis, Harvard University, Cambridge, Massachusetts.

Habte, M. \& Alexander, M. (1978). Mechanisms of persistence of low numbers of bacteria preyed upon by protozoa. Soil Biology and Biochemistry 10, $1-6$.

Hamilton, R. D. \& Preslan, J. E. (1970). Observations on the continuous culture of a planktonic phagotrophic protozoan. Journal of Experimental Marine Biology and Ecology 5, 94-104.

HöFLE, M. G. (1983). Long-term changes in chemostat cultures of Cytophaga johnsonae. Applied and Environmental Microbiology 46, 1045-1053.

Jost, J. L., Drake, J. F., Fredrickson, A. G. \& TsuchiYA, H. M. (1973). Interactions of Tetrahymena pyriformis, Escherichia coli, Azotobacter vinelandii, and glucose in a minimal medium. Journal of Bacteriology 113, 834-840.

Nanney, D. L. \& MCCoy, J. W. (1976). Characterization of the species of the Tetrahymena pyriformis complex. Transactions of the American Microscopical Society 95, 664-682. 
Novick, A. \& Szilard, L. (1950). Description of the chemostat. Science 112, 715-716.

SALT, G. W. (1975). Changes in the cell volume of Didinium nasutum during population increase. Journal of Protozoology 22, 112-115.

SAMBANIS, A. (1985). Experimental and modeling studies on the dynamics of cultures of the ciliate Tetrahymena pyriformis grown on several bacterial species. $\mathrm{PhD}$ thesis, University of Minnesota, Minneapolis.

Sambanis, A., Pavlou, S. \& Fredrickson, A. G. (1987). Coexistence of bacteria and feeding ciliates. Growth of bacteria on autochthonous substrates as a stabilizing factor for coexistence. Biotechnology and Bioengineering (in the Press).
SWIFT, S. T. (1981). Some aspects of the autecology of the ciliated protozoan, Tetrahymena pyriformis. PhD thesis, University of Minnesota, Minneapolis.

Swift, S. T., Najita, I. Y., Ohtaguchi, K. \& FredRickson, A. G. (1982). Continuous culture of the ciliate Tetrahymena pyriformis on Escherichia coli. Biotechnology and Bioengineering 24, 1953-1964.

TUNKEL, J. B. (1983). Selectivity in the feeding of Tetrahymena pyriformis on bacterial prey. MS thesis, University of Minnesota, Minneapolis.

Watson, P. J., OHTAGuchi, K. \& FREDrickson, A. G. (1981). Kinetics of growth of the ciliate Tetrahymena pyriformis on Escherichia coli. Journal of General Microbiology 122, 323-333. 